\title{
IWo tropical storms viewed by Apollo 7
}

Abstract

Introduction

The camera and film
Hurricane Gladys, near Florida, and typhoon Gloria, in the western Pacific Ocean, were photographed in October 1968 by the astronauts on the Apollo 7 spaceflight. Nearly concurrent weather satellite views are presented for comparison with these pictures to show scale differences and the cloud types that can be observed. In the view of Gladys the typical extensive cirrus cloud canopy was not present, permitting an exceptionally clear view of the convective cloud bands and other cloud structure. A photograph of typhoon Gloria showed organized, low-level cloud structure within its 50-mile diameter eye. The tropical storm pictures from Apollo 7 were obtained as part of a continuing effort to photograph, in color, Earth and cloud phenomena from manned spaceflights for use in environmental studies.

Two tropical storms were principal weather features that the Apollo 7 astronauts observed during the first manned spaceflight of the Apollo program. For five consecutive days in October 1968, Walter Schirra, Jr., Walter Cunningham, and Donn Eisele photographed hurricane Gladys in the vicinity of Florida. On another day they obtained pictures of typhoon Gloria in the western Pacific Ocean. These tropical storm pictures were taken as part of the Synoptic Weather Photography experiment, the objective of which was to photograph, in color, Earth and cloud phenomena for use in the environmental sciences. Other camera systems on unmanned satellites also took pictures of these storms, and these views will be compared and discussed with those from Apollo 7.

The Synoptic Weather Photography experiment, for which the authors were co-experimenters, was conducted on many of the Gemini spaceflights, and more than a thousand color photographs have been acquired. The variety of cloud patterns in the tropics and subtropics is so great, however, that each mission has contributed something new and significantly different from the others. Major uses of these pictures, which clearly show cloud details, are in the interpretation of weather satellite views and in the teaching of the interpretation process. The scale of the typical Gemini and Apollo pictures is intermediate between that seen by an observer on the ground, or in aircraft, and that seen in meteorological satellite views. This larger scale provides a wealth of detail and improves the understanding of the latter views, although the area covered is smaller. Such color photographs are available only infrequently, while the operational ESSA meteorological satellites provide daily global coverage. Research spacecraft, like the Applications Technology Satellites, provide views of the Earth also, but they are not yet routinely available for operational use. Such use is planned for the near future. During the Apollo 7 mission, however, ATS views were made available in time for use in the Weather Bureau's operational weather support of the mission-through special efforts of the NASA Goddard Space Flight Center and the ESSA National Environmental Satellite Center. Approximately concurrent coverage of hurricane Gladys was provided by ESSA 7 and ATS III, and ESSA 7 pictures of typhoon Gloria were available for comparison with the Apollo 7 views.

As in most previous manned spaceflights a modified hand-held 70-mm Hasselblad 500C camera with an $80-\mathrm{mm}$ focal length, $\mathrm{f} / 2.8$ lens, was used. Seven magazines of color fi!m with a total capacity of approximately 500 pictures were carried on the spaceflight for the photographic requirements. In addition to the Synoptic Weather Photography 


\section{A history of Gladys}

\author{
Gladys as viewed \\ from above
}

experiment, the astronauts conducted a similar effort, the Synoptic Terrain Photography experiment, to obtain views of the Earth's landforms for geological studies. Some film was used also to document the flight for engineering and operational aspects of the flight.

Kodak Medium Speed Ektachrome film, SO-368, with an exposure index of ASA 64, was carried in two film magazines. No filter was used with this film. The remaining five magazines contained Kodak High Resolution Aerial Ektachrome film, SO-121, having an aerial exposure index of 6 . A Wratten $2 \mathrm{~A}$ filter was attached to the camera lens when four of the five magazines were exposed.

After several days of organizing and intensifying, the seventh tropical storm of the year was named Gladys on 15 October 1968. The young disturbance drifted slowly northward between the Yucatan Peninsula and Jamaica but was initially rather poorly organized. Winds near the ill-defined center were near $50 \mathrm{kt}$ and steering currents at upper levels were very weak. Heavy rain fell on western Cuba and a hurricane watch was set in southern Florida.

On 16 October, at mid-day, an ESSA aircraft flying in the storm reported winds near hurricane force close to the center. Later in the day after passing over western Cuba the storm began to intensify. Hurricane warnings then were displayed along the west coast of Florida from the Keys to Clearwater. Northward movement continued at $10 \mathrm{kt}$ or less for the next two days, as the hurricane's center stayed just east of the 84th meridian.

Aircraft reconnaissance and radar reports indicated no clearly defined eye at times on 17 October, when the storm was nearly stationary, but late on that day there was some movement toward the north-northwest, when the storm was west of Venice, Fla. The track turned toward the northeast about noon on 18 October, and Gladys approached the coast of west-central Florida at a speed of 6 to $8 \mathrm{kt}$. Early on 19 October winds up to $82 \mathrm{kt}$ lashed Inglis as the eye moved inland between Homosassa and Crystal River. Her speed accelerated to $15 \mathrm{kt}$ as Gladys moved northeastward through the night, passing near Ocala and St. Augustine. This hurricane caused only moderate rainfall over Florida. Once over the warm waters of the Gulf Stream in the Atlantic Ocean on 19 October, the storm became more vigorous and moved rapidly northeastward.

It crossed Cape Hatteras early on the morning of 20 October. Winds of hurricane force continued near the center until Gladys became an extratropical low on 21 October southwest of Halifax, Nova Scotia.

The cover photograph of hurricane Gladys was taken on 17 October 1968, at 1531 GMT (1031 EST) when Apollo 7 was at an altitude of $99 \mathrm{n} \mathrm{mi} \mathrm{over} \mathrm{the} \mathrm{Gulf} \mathrm{of} \mathrm{Mexico} \mathrm{be-}$ tween the Mississippi River delta and the Florida Keys. At the time of this picture, taken toward the southeast, the central area of the storm was located about $120 \mathrm{n} \mathrm{mi}$ due west of Naples, Fla. Most land areas were hidden by clouds, but in this picture Cape Sable, Fla., is faintly discernible, as is the northern coast of Cuba near Havana. Between these two places are the Florida Keys, around which the shallow water appeared as a thin, light line.

Tropical storms usually generate much cirriform cloudiness which hides the lower cloud structure from view in space photographs. On this day most of the cirrus canopy was missing, which permitted an exceptional glimpse of Gladys's anatomy, particularly the great cumuliform cloud bands. Most of the cirrus was in the north and northeast sectors of the storm. It had been stationary for the previous several hours with little change in intensity. An ESSA aircraft flying near the center reported maximum winds at $65 \mathrm{kt}$ and a central air pressure of $986 \mathrm{mb}$.

The circular cap of cirrostratus near the hurricane's center marked an active region of convection probably close to the wall of the eye area. The cloud's diameter was about 10 to $12 \mathrm{n} \mathrm{mi}$. These pancake-like clouds have been seen a number of times in space photographs of areas with vigorous convection. The buoyant air within these convective cells may rise to the tropopause where further ascent is inhibited by the atmosphere's stability. The Key West rawinsonde ascent for 1200 GMT measured the tropopause height at $54,000 \mathrm{ft}$.

In the relatively clear air toward the lower right of this view, numerous rows of small cumulus clouds can be seen, oriented at an angle to the larger convective cloud bands. 
The row spacing was approximately three-quarters of a mile. The altitude of the cloud tops probably was 3 to 5 thousand feet with a tendency to become higher farther south. If it is assumed that the cloud rows were aligned parallel to the low-level wind direction, then the large-scale convective cloud bands curved to the left of the low-level wind flow.

A series of billows aligned nearly east-west in the thin stratiform clouds is evident in the lower left corner. Billows such as these normally are associated with vertical wind shear near a stable layer.

The very long line of cumulus congestus clouds beyond the center of the hurricane stretched from near western Cuba, across the Florida Keys near Key West, to the northern side of the center, a distance exceeding $400 \mathrm{n} \mathrm{mi}$. At 1500 GMT, 30 minutes before a crew member in Apollo 7 took the photo, a light rainshower was reported at Key West, probably from a cloud in this line.

The 1200 GMT rawinsonde measurements at Key West revealed some interesting features which may be indicative of the atmosphere's state outside the long cloud line. Since the rawinsonde ascent was made three and one-half hours before the cover picture was taken, the long cloud band was probably located west of Key West. A moist layer was present from the surface to $12,000 \mathrm{ft}$, showing a range in relative humidity from 75 to $94 \%$. Above this layer, up to $34,000 \mathrm{ft}$, was a drier region with humidities ranging from 22 to $38 \%$. Two stable layers were evident: an isothermal layer between 4000 and $6000 \mathrm{ft}$ and a slightly less stable region between 12,000 and 13,000 ft. These warmer layers may indicate that the air was subsiding outside the convective cloud band. South winds prevailed from the surface to $12,000 \mathrm{ft}$, ranging between 21 to $37 \mathrm{kt}$. Above this altitude, up to $47,000 \mathrm{ft}$, the wind direction was south-southwest to southwest at speeds of 23 to $46 \mathrm{kt}$. The atmospheric structure at Key West was dominated by the

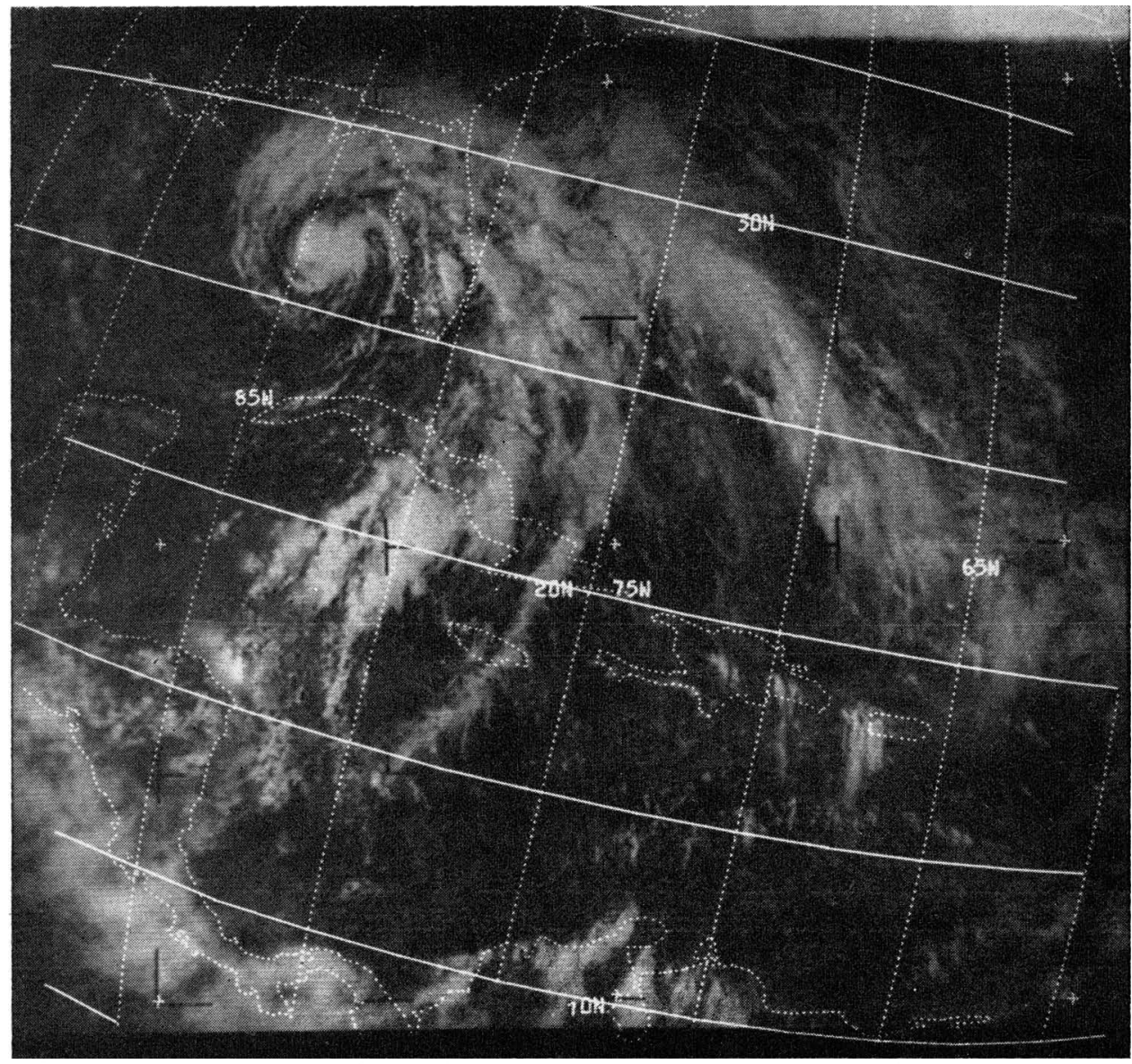

Fig. 1. ESSA 7 view of hurricane Gladys centered west of Florida on 17 October 1968, at 1934 GMT. 


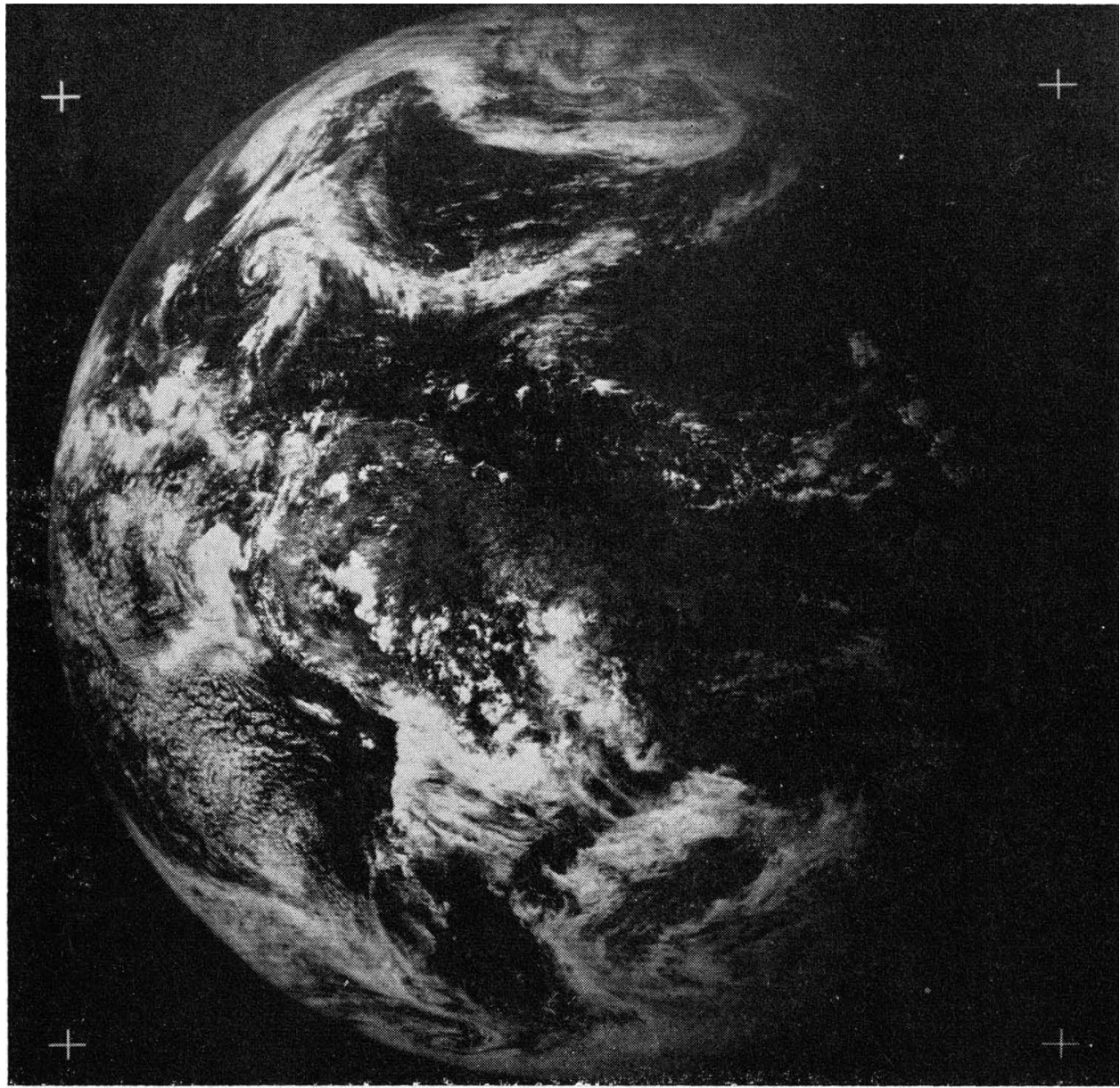

Fig. 2. View of hurricane Gladys (upper left) from ATS III on 17 October 1968, at 1707 GMT.

hurricane's circulation and was not typical of that found in a trade-wind regime. The stable layers were not present in the Tampa or Miami rawinsonde measurements. Those cities are just outside, to the left, of the area included in the cover photograph.

At 1934 GMT, four hours after the cover photograph was made, ESSA 7 took the picture of Gladys in Fig. 1 from an altitude of $780 \mathrm{n} \mathrm{mi}$. While the major cloud features of the hurricane are recognizable, the lower resolution does not permit the cloud types to be identified as readily as can be done in the Apollo 7 photograph. In the Apollo 7 picture the resolution in the area of the clouds near the center of Gladys is probably $400 \mathrm{ft}$, or approximately 50 times better than in the storm area in the ESSA 7 picture.

Fig. 2 is one of the excellent views taken by ATS III during this period. That geosynchronous satellite was over the equator above $47^{\circ}$ longitude, at an altitude of 19,400 $\mathrm{n} \mathrm{mi}$. This picture was made by the spin-scan camera system at 1707 GMT, 17 October 1968. The cloud vortex of the hurricane is located at the upper left of the picture. The resolution here is 3 to 4 times less than for the ESSA 7 view in Fig. 1 and 150 to 200 times less than for the Apollo 7 cover photograph. At the ATS III sub-satellite point, which is near the mouth of the Amazon River, the resolution is approximately $2 \mathrm{n}$ mi.

A technique for producing greater clarity in the ATS photographs with the aid of a computer was used to construct the picture of Gladys that is shown in Fig. 3. That digital process uses the data from the original telemetry to make sectional enlargements of the regular ATS picture. The cirriform and cumuliform clouds are about as easy to recognize in the digitally enlarged photograph as in the ESSA 7 view. 


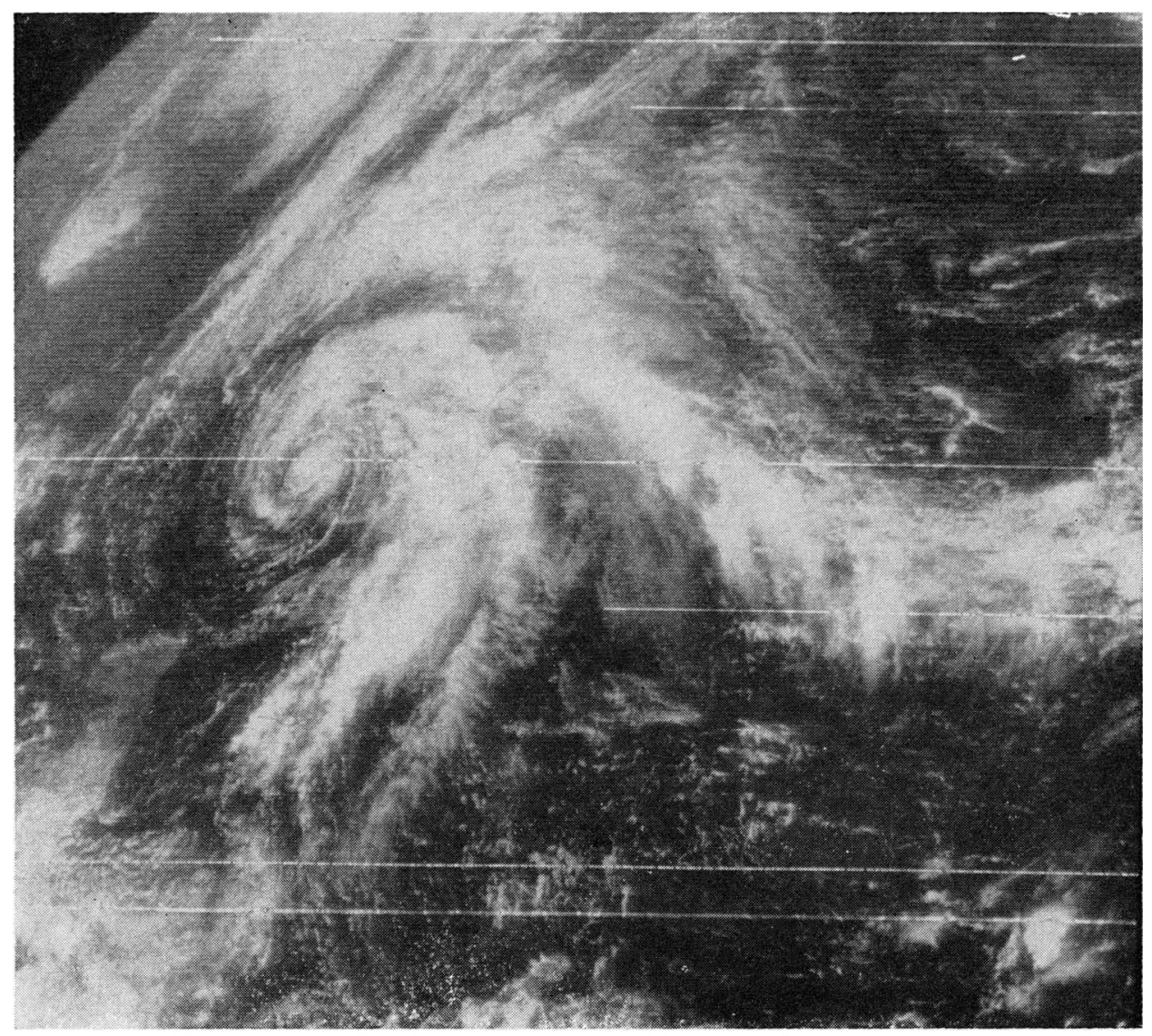

FIG. 3. Photograph of hurricane Gladys produced by computer from ATS III data on 17 October 1968, at 1707 GMT.

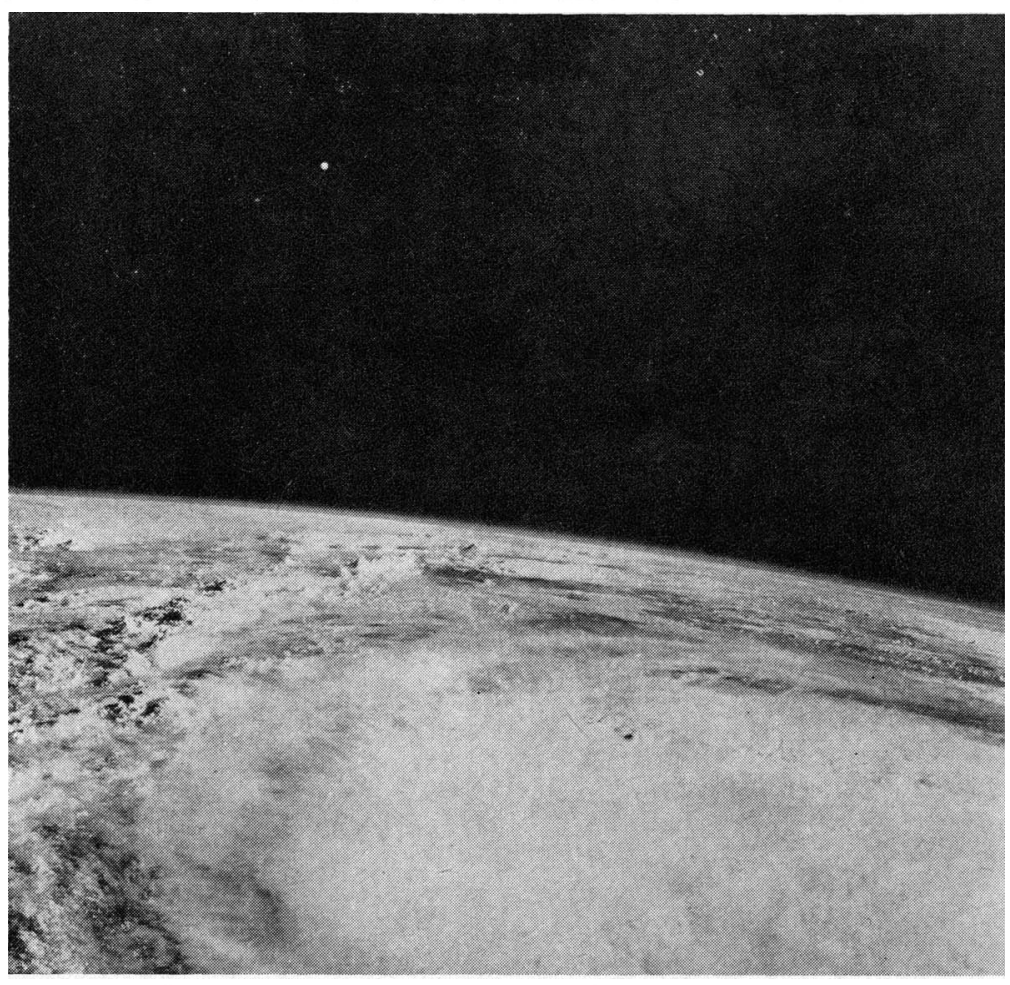

FIG. 4. Apollo 7 photograph of hurricane Gladys's northern region off Jacksonville, Fla., on 19 October 1968, at 1350 GMT. 
Many of the views taken during the five days on which hurricane Gladys was photographed showed extensive, relatively featureless clouds. Fig. 4 shows the northern sector of the storm on 19 October 1968, at 1350 GMT, two days after the cover picture was made. Early morning sunlight illuminated the cloud tops of the dense cirrus and cirrostratus over the storm. Its center was $40 \mathrm{n} \mathrm{mi} \mathrm{southeast} \mathrm{of} \mathrm{Jacksonville} \mathrm{at} \mathrm{the} \mathrm{time} \mathrm{of}$ this northeasterly view. Here the thick cirrus cloud canopy is in sharp contrast to the sparse cover the storm had on 17 October. Cloud protrusions in the top are indicative of intense convective activity below. Note also the numerous billows in the cirrostratus at the lower center. To the left, the cirrus cloud canopy ends abruptly and wisps of cirrus near the edge are aligned at an angle to a radial line.

Gladys was moving northeastward at $15 \mathrm{kt}$ at this time, and winds near the center were estimated at 85 to $90 \mathrm{kt}$. The central pressure had dropped to $965 \mathrm{mb}$.

\section{Typhoon Gloria}

Astronauts have photographed tropical storms during previous spaceflights but no picture has shown the eye of a storm as clearly as the one taken by the Apollo 7 crew, shown here as Fig. 5. This is how the center of typhoon Gloria appeared on 20 October 1968, at 0026 GMT over the western Pacific Ocean about $480 \mathrm{n} \mathrm{mi} \mathrm{south} \mathrm{of} \mathrm{Kyushu,} \mathrm{Japan.}$ Several hours prior to this time the astronauts were alerted to their forthcoming passage over Gloria and hence were ready to take this picture.

The viewing direction is toward the southeast and the local time is 9 a.m. The eye's diameter is approximately $50 \mathrm{n} \mathrm{mi}$. Visible within the eye are low-level cumuliform clouds which tend to form curved rows. Two centers of curvature in the nearer (north-

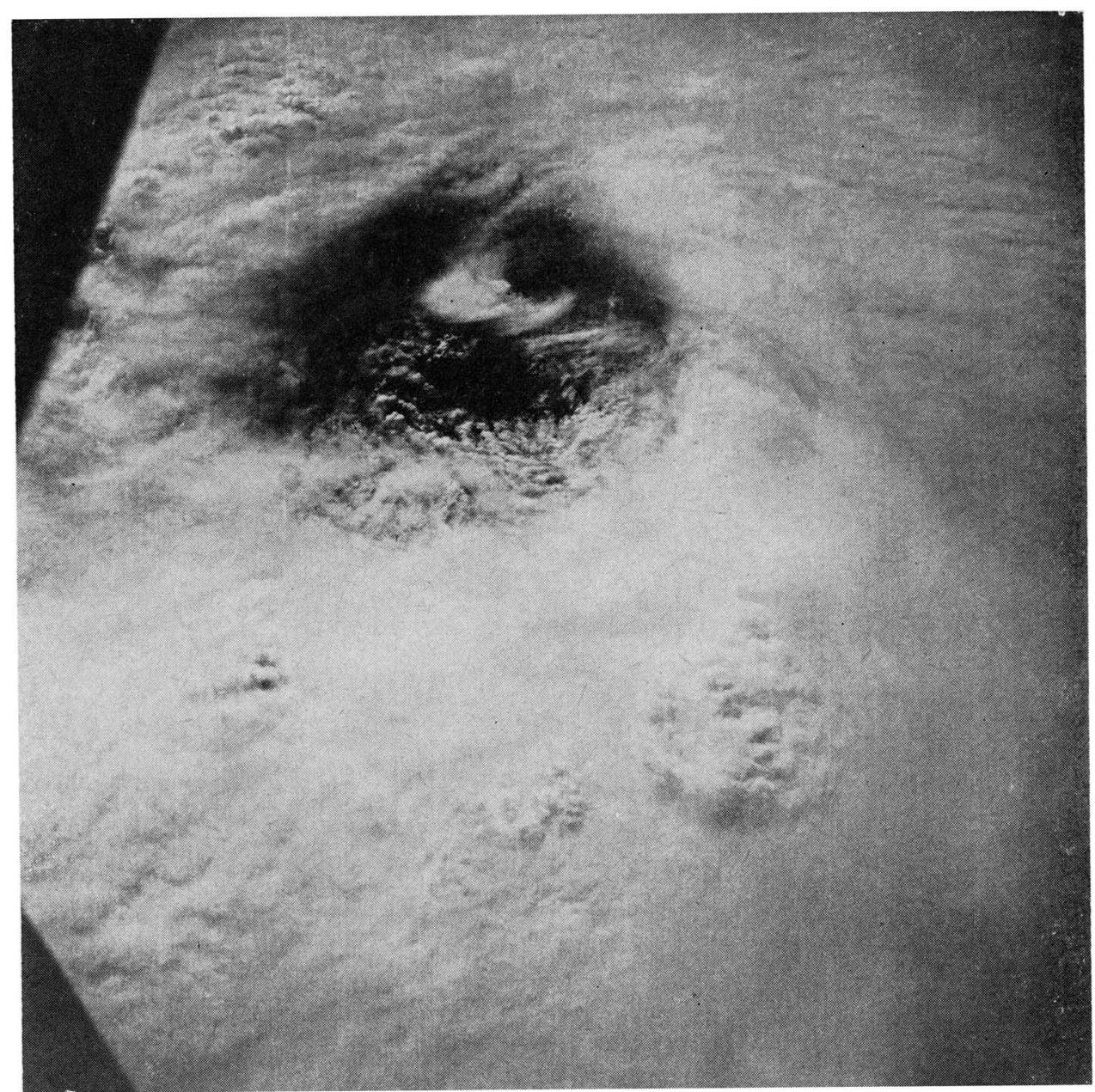

Fig. 5. Center of typhoon Gloria south of Japan as photographed from Apollo 7 on 20 October 1968, at 0026 GMT. 
ern) half of the eye are apparent. These may indicate that within the eye, where air motion is relatively light, mesoscale eddies are formed by the rapidly moving air near the wall cloud region. Over the eye's center a small cirrus cloud seems to twist counterclockwise and cast its shadow upon the lower clouds.

For comparison an ESSA 7 picture of typhoon Gloria is presented in Fig. 6. It was taken on 20 October 1968, at 0505 GMT, about 4-1/2 hours later than Fig. 5. Most of the cloud pattern associated with the typhoon can be seen. The cloud shield extended over $500 \mathrm{n}$ mi from east to west and the large eye is visible near the center.

\section{Outlook}

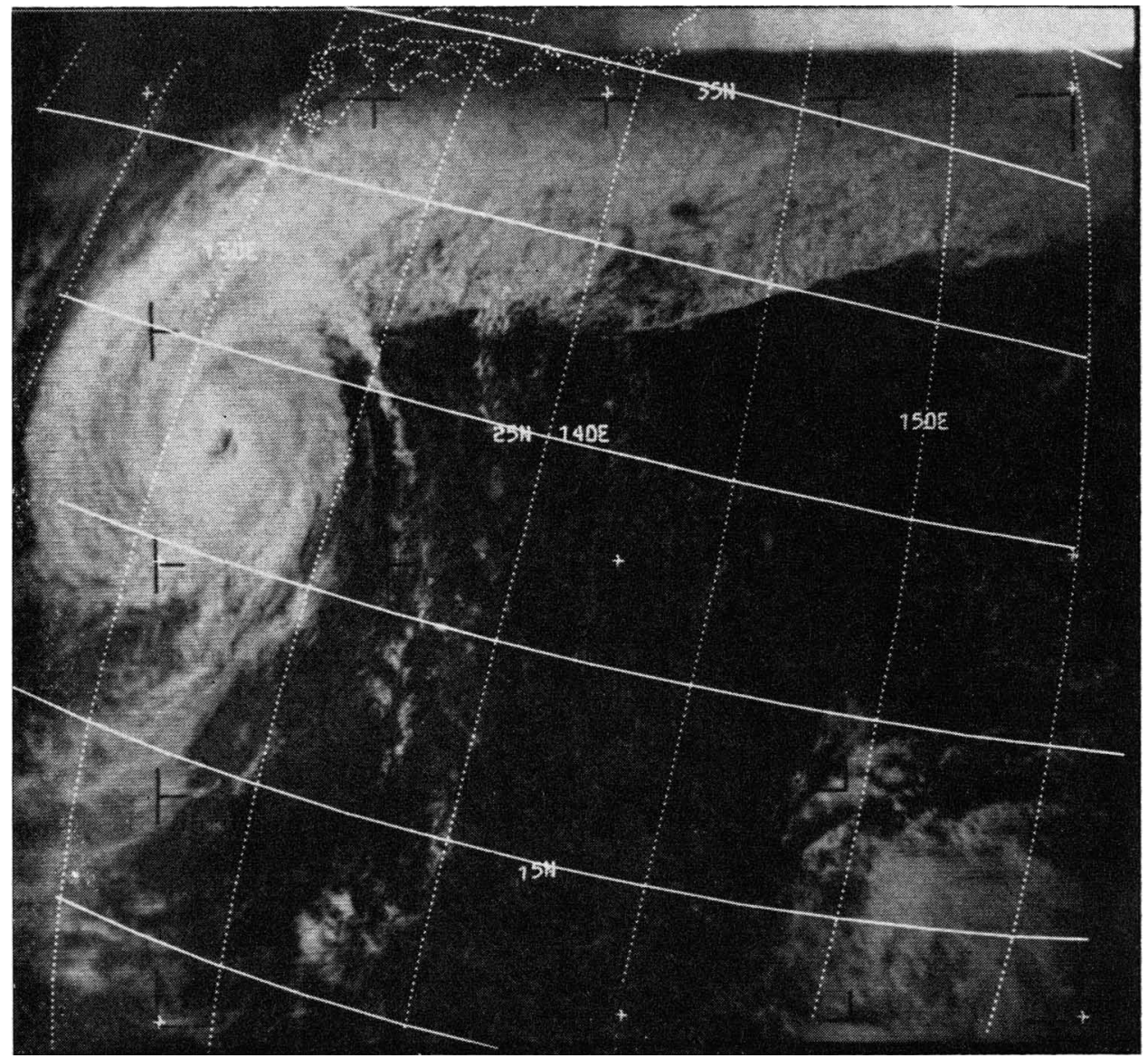

FIg. 6. ESSA 7 view of typhoon Gloria in the western Pacific Ocean on 20 October 1968, at 0505 GMT. 


\section{Acknowledgments}

\section{References}

Photographs on color film from the Gemini spaceflights have been disccussed previously (for example, Nagler and Soules, 1965; and Kuettner and Soules, 1966) to illustrate how these pictures can augment atmospheric studies when used in conjunction with regular weather observations and meteorological satellite views. In the two years since the last Gemini flight, pictorial coverage from meteorological satellites has greatly improved, making it possible for more extensive studies to be undertaken.

Many hundred color views obtained from the Gemini flights are shown and discussed in each of two excellent NASA publications: Earth Photographs from Gemini III, IV, and $V$, and Earth Photographs from Gemini VI through XII.

Astronauts on future spaceflights will also be taking pictures of the Earth's cloud system, although no specific weather photography experiment is planned for these flights. There will be continuing cooperation of ESSA and many other agencies in selecting meteorological targets and in interpreting the resulting pictures.

We are sincerely grateful to the astronauts of Apollo 7, Capt. Walter M. Schirra, Jr., Maj. Donn F. Eisele and Walter Cunningham, and to many others at the NASA Manned Spacecraft Center for assisting in the Synoptic Weather Photography Experiment. The ATS III photographs were provided by the NASA Goddard Space Flight Center.

Kuettner, J. P., and S. D. Soules, 1966: Organized convection as seen from space. Bull. Amer. Meteor. Soc., 47, 364-370.

Nagler, K. M., and S. D. Soules, 1965: Cloud photography from the Gemini 4 spaceflight. Bull. Amer. Meteor. Soc., 46, 522-527.

National Aeronautics and Space Administration, 1967: Earth photographs from Gemini III, IV, and V. NASA SP-129. U. S. Government Printing Office, Washington, D. C., 266 pp.

National Aeronautics and Space Administration, 1969: Earth photographs from Gemini VI through XII. NASA SP-171. U. S. Government Printing Office, Washington, D. C., 327 pp. (in press).

\section{announcements}

\section{New environmental research institute at Boulder}

The Environmental Science Services Administration and the University of Colorado have jointly announced formation of a Cooperative Institute for Research in the Environmental Sciences (CIRES) on the university's Boulder campus. This Institute is designed to promote research and teaching in solid earth geophysics, oceanography, radio propagation, the physics of the upper and lower atmospheres, and solar-terrestrial relationships, and to serve as a center for multi-disciplinary collaboration of research workers from Boulder and the entire world.

A visiting fellowship program provides funds to enable scientists working in these fields to spend a period of time, normally a year, with CIRES.

Further information may be obtained from the Cooperative Institute for Research in Environmental Sciences, University of Colorado, Boulder, Colo. 80302 USA.

\section{Summer institute in geophysical fluid mechanics}

A National Science Foundation Summer Institute in Geophysical Fluid Mechanics for teachers in engineering and science will be held from 23 June to 15 August 1969 at Colorado State University. The institute will offer interdisciplinary oriented courses in the mechanics of geophysical fluids, turbulent transport phenomena, metrology of fluid mechanics, Fourier analysis of geophysical data, and numerical analysis of geophysical flows. Courses may be taken for graduate credit. Applications and requests for additional information should be addressed to Dr. J. E. Cermak, Professor-in-Charge, Fluid Mechanics Program, Colorado State University, Fort Collins, Colo. 80521.

(More announcements on page 79) 


\section{Meteorological Monographs}

Vol. 9, No. 31, 231 pages, April 1968

Price: \$5 AMS members

$\$ 10$ nonmembers

\section{METEOROLOGICAL INVESTIGATIONS}

\section{OF THE \\ UPPER ATMOSPHERE}

Proceedings of the American Meteorological Society's Symposium on Meteorological Investigations Above 70 Kilometers, Miami Beach, 1967

- International in scope, the monograph presents reviews and stimulating appraisals of the current state of knowledge of the upper atmosphere, with emphasis on the complex region of the upper mesosphere and lower thermosphere. The Symposium was conceived by the AMS Committee on Atmospheric Problems of Aerospace Vehicles, in response to the need for improved knowledge of the environment traversed by reentry and other vehicles.

Edited by R. S. Quiroz,

Environmental Science Services Administration

- Contains 24 major papers in logical sequence, treating both theoretical and observational aspects of upper atmosphere research, supplemented by detailed summaries of six panel discussions concerned with special problem areas.

Send orders to:

AMERICAN METEOROLOGICAL SOCIETY

45 Beacon St., Boston, Mass. 02108 